\title{
A prospective, open label, 24-week trial of methylcobalamin in the treatment of diabetic polyneuropathy
}

\author{
Jacqueline C. Dominguez*, Arlene R. Ng, Ludwig F. Damian \\ Institute for Neurosciences, St. Luke's Medical Center, Quezon City, Philippines; \\ *Corresponding Author: jcdominguez@stluke.com.ph
}

Received 19 August 2012; revised 20 September 2012; accepted 29 September 2012

\section{ABSTRACT}

Introduction: Vitamin B complex has been used for peripheral neuropathy for a long time and continues to be part of current practice despite lack of strong evidence for its use and its non-inclusion in treatment guidelines. Objective: To determine the clinical and neurophysiological effects of $1500 \mu \mathrm{gm} /$ day of oral methylcobalamin among subjects with diabetic polyneuropathy. Methodology: We conducted a prospective, open-label study on adult diabetic subjects with polyneuropathy who were given $1500 \mu \mathrm{gm} /$ day of oral methylcobalamin over 24 -weeks. The primary outcome measure was the Toronto Clinical Scoring System (CSS) and secondary measures were Subjective Impression of Change, Clinicians Impression of Change and neurophysiological parameters. Results: Out of forty eight subjects, thirty seven completed treatment and twenty one agreed to have repeat neurophysiologic study post-treatment. At the end of treatment, there was a significant decline in the Toronto CSS score $(p<0.0001)$ indicating improvement. This was observed across all stages of severity and in any duration of diabetes whether more or less than 10 years. The symptoms that improved compared to baseline and that did not emerge over the course of 24 weeks were tingling ( $<<0.03)$, upper limb symptoms $(p<0.003)$, ataxia $(p<0.004)$, and signs of impaired position $(p<0.009)$ sense, vibration sense $(p<0.0001)$, pinprick sensation $(p<0.004)$ and knee reflex ( $p<0.004)$. No significant improvement was seen in the secondary outcomes (both $p=0.06$ ) except for ulnar nerve amplitude and distal latency. Conclusion: This 24-week open label study demonstrated that symptoms of diabetic polyneuropathy significantly im- proved among subjects given methylcobalamin $1500 \mu \mathrm{gm} /$ day and new symptoms did not emerge over the 24 week observation period. Larger controlled trials are needed to corroborate these findings.

Keywords: Methylcobalamin; Diabetic

Polyneuropathy; Therapeutics; Clinical Trial

\section{INTRODUCTION}

Diabetes is a globally prevalent condition [1] and peripheral neuropathy is one of its major chronic complications [2]. Together with other diabetic vascular complications such as stroke and heart disease, diabetic polyneuropathy (DPN) contributes to increased frequency of hospitalization among diabetics because of injuries, ulceration and eventual amputation. The pathologic mechanism in DPN is a complex interaction of the metabolic and vascular pathways that lead to axonal destruction and demyelination. Hyperglycemia promotes the accumulation of sorbitol and glycosylation of structured nerve proteins; increased endovascular resistance and hemorrheological abnormalities reduce blood flow; nerve ischemia generates reactive oxygen species with activetion of protein kinases; expression of nerve growth factors (NGF) is reduced. Some of these pathologic mechanisms have been targets of therapeutic investigations $[3,4]$.

Quality of life in DPN is diminished due to chronic pain symptoms and associated depression. Painful paresthesias are only temporarily relieved by anti-depressants $[5,6]$ or anticonvulsants $[7,8]$. Moreover, drug-related adverse events such as nausea and vomiting [5], dizziness and somnolence [7] may not be tolerated by patients and since DPN is a chronic condition, drug tolerance over time is possible. The availability, affordability and safeness of vitamin B complex make it frequently prescribed for any-cause neuropathy even if efficacy is un- 
clear. A Cochrane meta-analysis in 2008 showed that vitamin B only provides inconsistent short-term improvement and is not better than placebo in terms of pain relief [9]. The meta-analysis recommended more clinical trials to establish the efficacy of which specific Vitamin B for which particular neuropathy. This study evaluated the clinical and neurophysiological effects of methylcobalamin (vitamin B12) in subjects with DPN.

\section{MATERIALS AND METHODS}

This study was an investigator initiated open-label clinical trial. It was approved by the St. Luke's Medical Center Institutional Ethics Review Board. Informed consent was taken from all study subjects. Inclusion criteria were: 1) diabetes mellitus diagnosed by elevated fasting blood sugar $>126 \mathrm{mg} / \mathrm{dl}$ on two occasions or elevated glycosylated hemoglobin $(\mathrm{HgbA1C})>6.5 \%$ and the diagnosis confirmed by a physician; 2) polyneuropathy based on the presence symptoms, signs and neurophysiologic evidence for neuropathy [10]. Subjects with no dependable companion to supervise medications, or with poorly-controlled blood sugar described as $\mathrm{HgbA1C}$ $\geq 8 \%$ were excluded. Other conditions that confound reliable clinical assessment of neuropathy such as stroke, dementia or psychiatric illness, limb symptoms from other etiology like lumbosacral or cervical radiculopathy, carpal tunnel syndrome and other focal neuropathies were reasons for exclusion.

All subjects received baseline physical and neurologic examination. Toronto Clinical Scoring System (CSS) was used for detailed neuropathy assessment and rating of severity. This scale was chosen because it was shown to be useful in monitoring symptoms and has good morphologic correlation [11]. Vibration sense was tested with $128 \mathrm{~Hz}$ tuning fork applied on the fourth digit of the lower extremity. Subject's Impression Change (SIC) and Clinician's Impression of Change (CIC) were rated by the subject and physician respectively on a scale of $0-7$ : 1 (very much worse), 2 (moderately worse), 3 (minimally worse), 4 (no change), 5 (minimally improved), 6 (moderately improved) and 7 (very much improved) when compared to baseline. Subjects were clinically assessed periodically at $6,12,18$ and 24 weeks and the investigators were blinded to all their previous Toronto CSS ratings. Baseline neurophysiological assessment was done using Viking 4 electomyography machine (Nicolet, USA). Conduction velocities of the median, ulnar, peroneal, posterior tibial and sural nerves were measured using surface electrodes and their amplitudes were determined using the first negative peak. All conduction velocity studies were adjusted to the effects of temperature and compared to normative values standardized to the St. Luke's Neurophysiology laboratory for the diagnosis of neuropathy. Neurophysiological testing was repeated at end of study using the same machine, and the neurophysiologist was blinded to all clinical ratings. All subjects were given $500 \mu \mathrm{gm}$ of methylcobalamin tablets (Methycobal $^{\circledR}$, HI-Eisai Ltd., Makati) taken one per Orem three times a day for 24 weeks. A treatment diary was given to the subjects or their respective companions to track intake of the study medication. Treatment compliance was checked by the study coordinator in between visits. Throughout the study, all subjects received medical care by their personal physicians including anti-diabetic medications and usual dietary advice.

Mean, standard deviation and frequency were used for descriptive statistics. Differences in mean values between groups were analyzed by paired t-test. Multiple comparisons using Sidak procedure was done to determine the differences in Toronto CSS scores between different evaluation periods. Analysis of covariance was done to determine the effect of methylcobalamin in the subgroup analysis with severity of neuropathy and duration of diabetes as covariates. All statistical tests were 2 sided and $\mathrm{p}$ value $<0.05$ was considered as statistically significant. The primary outcome measure was decline in Toronto CSS score post-treatment which indicates improvement. Secondary measures were increase in Subjective Impression of Change (SIC) and Clinicians Impression of Change (CIC), and improvement in means of neurophysiological parameters. A decrease in Toronto CSS score by $\geq 2$, and consistent increase in SIC and CIC at 12 and 24 weeks were considered significant. Stata 11 data analysis and statistical software was used.

\section{RESULTS}

Forty eight subjects participated and eleven were eventually excluded because of stroke (1), refusal to take medications because of dizziness (1), transfer of residence (1), non-compliance (4) and lost to follow-up (4). Thirty seven completed treatment and 21 subjects agreed to have post-treatment neurophysiological testing. The mean age of the subjects was $62.9 \pm 13.1$ years, majority were female $(60.5 \%)$, and the mean duration of diabetes was $10 \pm 16.6$ years, with almost half having diabetes longer than 10 years $(42.86 \%)$ Four of the 37 subjects were exclusively on insulin treatment while the rest were on oral hypoglycemic pills. The mean Toronto CSS score was $9.19 \pm 5.42$, and DPN was considered mild (40.48\%), moderate $(47.62 \%)$ or severe $(11.90 \%)$ by the Toronto CSS scores. Numbness (97.29\%), tingling (72.97\%) and upper limb symptoms $(54.04 \%)$ were the most frequent symptoms while the most frequent neurologic signs detected were diminished ankle reflex $(91.89 \%)$, impaired vibration sense $(86.48 \%)$ and diminished pinprick sensation $(67.56 \%)$. 
There was a significant overall decline in Toronto CSS score after the 24-week treatment period $(\mathrm{p}<0.0001)$. Multiple comparisons of Toronto CSS score at the different evaluation periods showed progressive significant decline starting at the 6th week of treatment $(p<0.05)$. Such improvement was seen across all stages of severity (mild, moderate and severe) and in any duration of diabetes whether more or less than 10 years.

The decrease in frequency of symptom post-treatment was highest in tingling $(48.15 \%)$, followed by weakness $(42.86 \%)$ and pain $(36.36 \%)$. Reversal of some symptoms that were present at baseline was observed post treatment and if such symptoms were absent at baseline, they did not emerge at the end of the 24 week treatment. Such observation was significant for tingling $(\mathrm{p}<0.03)$, upper limb symptoms $(\mathrm{p}<0.003)$, ataxia $(\mathrm{p}<0.004)$, as well as in signs of impaired position sense $(\mathrm{P}<0.009)$ and vibration sense $(\mathrm{p}<0.0001)$, pinprick sensation $(\mathrm{p}<$ $0.004)$ and right knee reflex $(p<0.004)$ (Table 1). Secondary outcome analysis did not show significant improvement post-treatment as indicated by the SIC and CIC (both $\mathrm{p}=0.06$ ) and in neurophysiological measures at 24 weeks except for ulnar nerve amplitude, conduction velocity and distal latency (Table 2).

\section{DISCUSSION}

The results of this study showed that $1500 \mu \mathrm{gm}$ of methylcobalamin taken daily for 24 weeks decreased the occurrence of the common and disturbing symptoms of DPN such as tingling, weakness and pain. Although a recent treatment guidelines for pain relief in DPN did not include Vitamin B in its recommendation [12] the results of this study support the use of methylcobalamin in clinical practice. The guidelines instead recommended the use of anti-epileptics and anti-depressants but their use may be limited by side-effects like dizziness, nausea, and somnolence. The retention rate in this study was $77.08 \%$ (37/48) with only one subject withdrawal related to adverse event i.e. dizziness. This result makes methylcobalamin a safe option especially among populations at risk for such adverse events like the elderly which comprised our study population (mean age of 62.9 \pm 13.1 years).

The occurrence and frequency of neuropathy symptoms is expected to increase over time among diabetics [13]. Results showed that subjects' symptoms did not only improve, but more notably new symptoms did not emerge over the 24 week observation period. The daily intake of methylcobalamin $1500 \mu \mathrm{gm}$ expectedly caused high levels of methylcobalamin which reportedly upregulates gene transcription [14] to increase protein synthesis necessary for nerve repair. Such mechanism could account for the improvement observed in the study.
Table 1. Change in the rating of individual items of the Toronto CSS score comparing baseline and post treatment.

\begin{tabular}{|c|c|c|c|}
\hline $\begin{array}{l}\text { Symptom } \\
\text { rating post } \\
\text { treatment }\end{array}$ & $\begin{array}{c}\text { Symptom } \\
\text { rating at } \\
\text { baseline } 0^{*} \\
\mathrm{~N}(\%)\end{array}$ & $\begin{array}{c}\text { Symptom } \\
\text { rating at } \\
\text { baseline } 1^{*} \\
\mathrm{~N}(\%)\end{array}$ & p-value \\
\hline \multicolumn{4}{|l|}{ Foot } \\
\hline $\begin{array}{c}\text { Pain } \\
0 \\
1\end{array}$ & $\begin{array}{c}23(88.5) \\
3(11.5)\end{array}$ & $\begin{array}{l}7(63.6) \\
4(36.6)\end{array}$ & 0.08 \\
\hline $\begin{array}{c}\text { Numbness } \\
0 \\
1\end{array}$ & $\begin{array}{c}1(100.0) \\
0\end{array}$ & $\begin{array}{c}1(19.4) \\
29(80.6)\end{array}$ & 0.054 \\
\hline $\begin{array}{c}\text { Tingling } \\
0 \\
1\end{array}$ & $\begin{array}{l}9(90.0) \\
1(10.0)\end{array}$ & $\begin{array}{l}14(51.8) \\
13(48.2)\end{array}$ & 0.03 \\
\hline $\begin{array}{c}\text { Weakness } \\
0 \\
1\end{array}$ & $\begin{array}{c}20(87.0) \\
3(13.0)\end{array}$ & $\begin{array}{l}9(64.3) \\
5(35.7)\end{array}$ & 0.10 \\
\hline $\begin{array}{c}\text { Ataxia } \\
0 \\
1\end{array}$ & $\begin{array}{c}27(93.1) \\
2(6.9)\end{array}$ & $\begin{array}{l}4(50.0) \\
4(50.0)\end{array}$ & 0.003 \\
\hline $\begin{array}{c}\text { UL } \\
\text { symptoms }^{+} \\
0 \\
1\end{array}$ & $\begin{array}{c}14(82.3) \\
3(17.7)\end{array}$ & $\begin{array}{c}7(35.0) \\
13(65.0)\end{array}$ & 0.004 \\
\hline $\begin{array}{c}\text { Reflexes }^{\mathrm{a}} \\
\text { right ankle } \\
0 \\
1\end{array}$ & $\begin{array}{l}2(40.0) \\
3(60.0)\end{array}$ & $\begin{array}{l}12(37.5) \\
20(62.5)\end{array}$ & 0.93 \\
\hline $\begin{array}{c}\text { Left ankle } \\
0 \\
1\end{array}$ & $\begin{array}{l}3(75.0) \\
1(25.0)\end{array}$ & $\begin{array}{l}11(33.3) \\
22(66.7)\end{array}$ & 0.10 \\
\hline $\begin{array}{c}\text { Right knee } \\
0 \\
1\end{array}$ & $\begin{array}{c}12(80.0) \\
3(20.0)\end{array}$ & $\begin{array}{c}7(31.8) \\
15(68.2)\end{array}$ & 0.004 \\
\hline $\begin{array}{c}\text { Left knee } \\
0 \\
1\end{array}$ & $\begin{array}{c}12(85.7) \\
2(14.3)\end{array}$ & $\begin{array}{c}7(30.4) \\
16(69.6)\end{array}$ & 0.001 \\
\hline $\begin{array}{c}\text { Sensory test } \\
\text { pin prick } \\
0 \\
1\end{array}$ & $\begin{array}{c}12(100.0) \\
0\end{array}$ & $\begin{array}{l}13(52.0) \\
12(48.0)\end{array}$ & 0.004 \\
\hline $\begin{array}{c}\text { Temperature } \\
0 \\
1\end{array}$ & $\begin{array}{c}27(90.0) \\
3(10.0)\end{array}$ & $\begin{array}{l}5(71.4) \\
2(28.6)\end{array}$ & 0.20 \\
\hline $\begin{array}{c}\text { Light touch } \\
0 \\
1\end{array}$ & $\begin{array}{c}10(76.9) \\
3(23.1)\end{array}$ & $\begin{array}{l}14(58.3) \\
10(41.7)\end{array}$ & 0.26 \\
\hline $\begin{array}{c}\text { Vibration } \\
0 \\
1\end{array}$ & $\begin{array}{c}5(100.0) \\
0\end{array}$ & $\begin{array}{c}4(12.5) \\
28(87.5)\end{array}$ & $<0.0001$ \\
\hline $\begin{array}{c}\text { Position } \\
0 \\
1\end{array}$ & $\begin{array}{c}17(89.5) \\
2(10.5)\end{array}$ & $\begin{array}{l}9(50.0) \\
9(50.0)\end{array}$ & 0.009 \\
\hline
\end{tabular}

${ }^{*} 0=$ absent, 1 = present; ${ }^{+}$Upper Limb; ${ }^{\text {a }}$ for this analysis, reflex score was rated as 1 if it was normal or 0 if it was decreased or absent. 
Table 2. Neurophysiological measures at baseline and post treatment.

\begin{tabular}{|c|c|c|c|c|}
\hline Nerve & Neurophysiologic measure & $\begin{array}{c}\text { Baseline } \\
\text { (mean, SD) }\end{array}$ & $\begin{array}{l}\text { Post treatment } \\
\text { (mean, SD) }\end{array}$ & $\mathrm{p}$-value* \\
\hline \multicolumn{5}{|l|}{ Motor } \\
\hline Ulnar & $\begin{array}{c}\text { Distal latency }(\mathrm{ms}) \\
\text { CV }(\mathrm{m} / \mathrm{s}) \\
\text { Amplitude }(\mathrm{mV}) \\
\text { F wave latency }\end{array}$ & $\begin{aligned} 2.9 & \pm 0.3 \\
52.7 & \pm 11.6 \\
9.1 & \pm 1.7 \\
27.6 & \pm 2.9\end{aligned}$ & $\begin{array}{c}2.8 \pm 0.4 \\
55.1 \pm 7.5 \\
9.6 \pm 1.8 \\
27.5 \pm 2.8\end{array}$ & $\begin{array}{l}0.02 \\
0.47 \\
0.03 \\
0.76\end{array}$ \\
\hline Tibial & $\begin{array}{c}\text { Distal latency (ms) } \\
\text { CV (m/s) } \\
\text { Amplitude (mV) }\end{array}$ & $\begin{aligned} 3.9 & \pm 1.4 \\
37.9 & \pm 13.8 \\
8.2 & \pm 5.6\end{aligned}$ & $\begin{aligned} 4.2 & \pm 1.2 \\
40.3 & \pm 10.5 \\
8.6 & \pm 5.0\end{aligned}$ & $\begin{array}{l}0.35 \\
0.31 \\
0.46\end{array}$ \\
\hline Peroneal & $\begin{array}{c}\text { Distal latency (ms) } \\
\text { CV (m/s) } \\
\text { Amplitude (mV) }\end{array}$ & $\begin{aligned} 3.8 & \pm 1.1 \\
42.1 & \pm 11.6 \\
3.4 & \pm 2.2\end{aligned}$ & $\begin{aligned} 3.5 & \pm 1.4 \\
43.0 & \pm 15.9 \\
3.6 & \pm 2.2\end{aligned}$ & $\begin{array}{l}0.38 \\
0.71 \\
0.57\end{array}$ \\
\hline \multicolumn{5}{|l|}{ Sensory } \\
\hline Ulnar & $\begin{array}{c}\mathrm{CV}(\mathrm{m} / \mathrm{s}) \\
\text { Amplitude }(\mu \mathrm{V})\end{array}$ & $\begin{array}{c}57.0 \pm 6.4 \\
23.3 \pm 11.4\end{array}$ & $\begin{array}{l}52.5 \pm 13.6 \\
22.5 \pm 12.7\end{array}$ & $\begin{array}{l}0.05 \\
0.73\end{array}$ \\
\hline Sural & $\begin{array}{c}\mathrm{CV}(\mathrm{m} / \mathrm{s}) \\
\text { Amplitude }(\mu \mathrm{V})\end{array}$ & $\begin{aligned} 30.9 & \pm 23.1 \\
7.8 & \pm 9.4\end{aligned}$ & $\begin{array}{c}32.8 \pm 22.9 \\
8.1 \pm 7.8\end{array}$ & $\begin{array}{l}0.68 \\
0.83\end{array}$ \\
\hline
\end{tabular}

${ }^{*} \mathrm{p}$-value significant at $\leq 0.50 \mathrm{CV}=$ conduction velocity.

The observation that methylcobalamin prevented the emergence of some symptoms could make methylcobalamin a serious consideration for use in pre-clinical DPN (asymptomatic but with characteristic abnormalities on neurophysiologic testing) to prevent or delay emergence of symptoms which can eventually become chronic and disabling. This view may yet be of particular importance in asymptomatic autonomic neuropathy which accounts for silent myocardial infarction among diabetics [15].

The significant improvement in the motor and sensory parameters of the ulnar nerve is consistent with the clinical improvement in upper limb symptoms noted in the Toronto CSS. The non-significant findings in the neurophysiological measures are similar with other studies of short observation period when the expected neurophysiologic change with treatment is very small to be detected. Studies should be done for as long as three years to detect significant improvement in DPN [16]. It would have been useful to know the effect of glycemic control in this study but subjects with poor diabetic control were excluded because these subjects usually have undetectable sensory and motor responses in the neurophysiologic study and any improvement in the neurophysiologic parameters would be difficult to detect given the short study duration. Aside from the restricted observation period, another limitation of this study is it's being open-labeled with small sample size. Even if so, clinicians were blinded to their previous Toronto CSS ratings thereby minimizing bias in their subsequent assessments. Other limitations are the non-inclusion in the analysis of the effect of glycemic control on the improvement of symptoms since not all of the subjects had periodic fasting blood sugar level monitored by their personal physicians during the course of the study, and the lack of external controls, this being an initial study to document if indeed there would be any improvement in the clinical and neurophysiologic parameters with intake of methylcobalamin. Admittedly, longer and larger double blind randomized placebo-controlled trials are needed to verify the findings in this study.

Unlike cyanocobalamin and hydroxycobalamin that need to be converted to methylcobalamin, methylcobalamin is the biologically active and natural form of vitamin B12 found in food. It is a co-factor in the transmethylation processes-conversion of methylmalonyl$\mathrm{CoA}$ to succinyl-CoA and in the regeneration of methionine from homocystein by methionine synthetase, therefore it has been used mainly in the treatment of hyperhomocysteinemia [17]. Methylcobalamin has also demonstrated its efficacy in DPN [18-20] but the exact mechanism is not known. One proposed mechanism is that methylcobalamin is a crucial and direct donor of methyl groups to the myelin sheath that insulates the axon and for DNA metabolism for nerve regeneration. But this is only one side of the dual metabolic-vascular pathology of DPN. Trials on the combination of methylcobalamin plus drugs that have been reported to be effective in DPN by principally exerting their effect on its vascular pathology e.g. cilostazol merits investigation to evaluate their potential combined efficacy. 


\section{CONCLUSION}

This open label study demonstrated that symptoms of neuropathy significantly improved among subject with DPN treated with methylcobalamin $1500 \mu \mathrm{gm} /$ day. In addition, new symptoms did not emerge over the 24 weeks observation period. Randomized placebo controlled trials are needed to corroborate these findings as well as trials with the use of combination of methylcobalamin and drugs that improve peripheral neural microvasculature.

\section{ACKNOWLEDGEMENTS}

Since this study is investigator initiated, the design, conduct, analysis, and publication of this study are exclusively the investigators' judgment. The authors are grateful to Eisai Japan Ltd. for supplying Methylcobalamin tablets and sponsoring the neurophysiological tests and to the Institute for Neurosciences (Dr. Greg Dayrit and Dr. Senna Lim) and Endocrine Center (Dr. Michael Villa and Dr. Lora Tan Tin Hay) for their support in recruiting patients into the study.

\section{REFERENCES}

[1] Wild, S., Gojka, R., Green, A., Sicree, R. and King, H. (2004) Global prevalence of diabetes. Estimates for the year 2000 and projections for 2030. Diabetes Care, 27, 1047-1053. doi:10.2337/diacare.27.5.1047

[2] Lu, B., Yang, Z., Wang, M., et al. (2010) High prevalence of diabetic neuropathy in population-based patients diagnosed with type 2 diabetes in the Shanghai downtown. Diabetes Research and Clinical Practice, 88, 289-294. doi:10.1016/j.diabres.2010.02.002

[3] Ramirez M.A. and Borja N.L. (2008) Epalrestat: An aldose reductase inhibitor for the treatment of diabetic neuropathy. Pharmacotherapy, 28, 646-655. doi:10.1592/phco.28.5.646

[4] Ziegler D., Nowak H., Kempler P., Vargha P. and Low, P.A. (2004) Treatment of symptomatic diabetic polyneuropathy with the antioxidant alpha-lipoic acid: A metaanalysis. Diabetic Medicine, 21, 114-121. doi:10.1111/j.1464-5491.2004.01109.x

[5] Raskin, J., Pritchett, Y.L., Wang, F., et al. (2005) A double-blind, randomized multicenter trial comparing duloxetine with placebo in the management of diabetic peripheral neuropathic pain. Pain Medicine, 6, 346-356. doi:10.1111/j.1526-4637.2005.00061.x

[6] Max, M.B., Lynch, S.A., Muir, J., Shoaf, S.E., Smoller, B. and Dubner, R. (1992) Effects of desipramine, amitriptyline, and fluoxetine on pain in diabetic neuropathy. The New England Journal of Medicine, 326, 1250-1256. doi:10.1056/NEJM199205073261904

[7] Lesser, H., Sharma, U., LaMoreaux, L. and Poole, R.M. (2004) Pregabalin relieves symptoms of painful diabetic neuropathy: A randomized controlled trial. Neurology, 63, 2104-2110. doi:10.1212/01.WNL.0000145767.36287.A1

[8] Raskin, P., Donofrio, P.D., Rosenthal, N.R. et al., the
CAPSS-141 Study Group (2004) Topiramate vs placebo in painful diabetic neuropathy: Analgesic and metabolic effects. Neurology, 63, 865-873. doi:10.1212/01.WNL.0000137341.89781.14

[9] Ang, C.D., Alviar, M.J.M., Dans, A.L., et al. (2008) Vitamin B for treating polyneuropathy. Cochrane Database Systematic Review, 3, Article No: CD004573. doi:10.1002/14651858.pub3.

[10] England, J.D., Gronseth, G.S., Franklin, G., et al. (2005) Distal symmetric polyneuropathy: A definition for clinical research: Report of the American Academy of Neurology, the American Association of Electrodiagnostic Medicine, and the American Academy of Physical Medicine and Rehabilitation. Neurology, 64, 199-207. doi:10.1212/01.WNL.0000149522.32823.EA

[11] Bril, V. and Perkins, B.A. (2002) Validation of the Toronto clinical scoring system in diabetic polyneuropathy. Diabetes Care, 25, 2048-2050. doi:10.2337/diacare.25.11.2048

[12] Bril, V., England, J., Franklin, J.M., et al. (2011) Evidence-based guideline: Treatment of painful diabetic neuropathy. Report of the American Academy of Neurology, the American Association of Neuromuscular and Electrodiagnostic Medicine, and the American Academy of Physical Medicine and Rehabilitation. Neurology, 76, 1. doi:10.1212/WNL.0b013e3182166ebe

[13] Partanen, J., Niskanen, L., Lehtines, J., et al. (1995) Natural history of peripheral neuropathy in patients with non-insulin dependent diabetes mellitus. The New England Journal of Medicine, 333, 89-94. doi:10.1056/NEJM199507133330203

[14] Watanabe, T., Kaji, R., Oka, N., Bara, W. and Kimura, J. (1994) Ultra-high dose methylcobalamin promotes nerve regeneration in experimental acrylamide neuropathy. Journal of the Neurological Sciences, 122, 140-143. doi:10.1016/0022-510X(94)90290-9

[15] Vinik, A.I. and Zeigler D. (2001) Diabetic cardiovascular autonomic neuropathy. Circulation, 115, 387-397. doi:10.1161/CIRCULATIONAHA.106.634949

[16] Dyck, P.J., Davies, J.L., Litchy, W,J and O'Brien, P.C. (1997) Longitudinal assessment of diabetic polyneuropathy using composite score in the Rochester Diabetic Neuropathy Study Cohort. Neurology, 49, 229-239. doi:10.1212/WNL.49.1.229

[17] Maron, B.A. and Loscalzo, J. (2009) The treatment of hyperhomocysteinemia. Annual Review of Medicine, 60, 39-54. doi:10.1146/annurev.med.60.041807.123308

[18] Yaqub, B.A., Siddique, A. and Sulimani, R. (1992) Effects of methylcobalamin on diabetic neuropathy. Clinical Neurology and Neurosurgery, 9, 105-111.

[19] Sun, Y., Lai, M.S., and Lu, C.J. (2005) Effectiveness of vitamin B12 on diabetic neuropathy: Systematic review of clinical controlled trials. Acta Neurol Taiwan, 14, 4854.

[20] Kuwabara, S., Nakazawa, R., Azuma, N, et al. (1999) Intravenous methylcobalamin treatment for uremic and diabetic neuropathy in chronic hemodialysis patients. Internal Medicine, 38, 472-475. 